\title{
Use of Alternative and Complementary Medicine by Old Italians Adults: The Determinant of Choice
}

\author{
Silvia Platania*, Giuseppe Santisi \\ Department of Educational Sciences, University of Catania, Catania, Italy \\ Email: splatani@unict.it
}

Received 22 June 2015; accepted 25 July 2015; published 28 July 2015

Copyright (C) 2015 by authors and Scientific Research Publishing Inc.

This work is licensed under the Creative Commons Attribution International License (CC BY).

http://creativecommons.org/licenses/by/4.0/

(c) (i) Open Access

\begin{abstract}
Complementary and alternative medicine (CAM) is the term for medical products and practices that aren't part of standard care. Although using complementary and alternative medicines (CAM) is becoming increasingly prevalent in Italy, research in complementary and alternative therapy in older adults is limited. This study investigates the predictors and the determinant of choice of using complementary and alternative medicine (CAM) in older adult consumers [1]-[3]. The sample consisted of 150 Italian older consumers who used alternative medicine in the last year. The older adults interviewed were 52 males $(34.7 \%)$ and 98 females $(65.3 \%)$ and the average age was 65.4 $(S D=0.76)$. The results of this study showed a strong dissatisfaction of respondents with the traditional medical treatments because the alternative's medicine treatments are considered more invasive.
\end{abstract}

\section{Keywords}

Consumption, Medicine, Behavior, Desire, Health, Older Adults

\section{Introduction}

In the last years, the purchase's motivation and the behaviors of the consumers have been the main points of many researches. The interest for those researches arises from the consideration, which is now universally accepted that consumption tends to get not only things or services, but also free time and all daily dimensions; through it there is an ongoing investigation by the consumer to meet their own needs in order to achieve personal well-being. The current notion of consumerism mainly concerns the role that the consumer has the interaction

*Corresponding author.

How to cite this paper: Platania, S. and Santisi, G. (2015) Use of Alternative and Complementary Medicine by Old Italians Adults: The Determinant of Choice. Open Journal of Social Sciences, 3, 293-299. http://dx.doi.org/10.4236/jss.2015.37042 
with self and identity. Purchasing a product means to know a story and identify with a new world meaning that "identity becomes imitation's game" [4].

In addition to the utilitarian logic there are new dimensions to approach the consumption: emotion, symbol, aesthetics, relation and desire. Indeed the desire's logic precedes (in chronological order) the rational-instrumental one: the desire is present from birth, while cognitive skills related to perception and learning will increase gradually and slowly [5]. The desire (instinct) and the imagination (the mode of mind which people try to achieve) are the first experiences of the world and together form the first important way to question and find out a positive reply to own need and well-being. The consumer society raises the logic of desire, usually hidden in a corner of the consumer's mind in order to enable post-modern people to explore again their relationship with the real, to make the feeling of lack of response and the sense of their needs tolerable. According to this point of view the consumption's self is a continuous representation of self-knowledge: "I'm just not what I am, but also what other people think of me and specially I represent what I am or what I want to be perceived by others through my consumer behavior" [6]. The self-knowledge can be regarded as an experience related to skills and competencies, successes and failures, values, aims and goals. In essence, this knowledge constitutes the choice to join a specific lifestyle. A special type of consumer that has evolved in recent years, moving from a mere passive consumer tied to the logic of utility to a consumer active and demanding, especially for what concerns his welfare, is the consumer called older adult. This one often determines his own choices based on his life style. The traditional idea of older adult is to believe that the members of the third age as a social category have limited needs; thanks to those researches this thought about the third age is changed. The most recent socio-economic report reveals that within the next forty years, people over sixty years in the world will be more than two billion and the percentage of older adults in the total population will rise from $24.5 \%$ to $37 \%$. The evolution of expectancy life has created a great revolution in socio-anthropological older adults because the consumer is the one who is able to dictate economic demand and to address their needs in a qualitative sense [7] [8]. The aging processes is a time when older adult, free from the burdens and difficulties of adulthood, can engage new stimulating hobbies: "The new version of longevity evolves over daily and is characterized by a process of continuous revision of the destinations, routes and strategies to achieve them" [9].

The new socio-affective dimension allows older adults to redesign their existence with new perspectives to reach a new wellness. The places where this research can be made coincide with consumer's experiences that allow the opportunity to develop lifestyles and identities that can become real stimulus for a new phase of own existence. The older adult consumers in Italy also belong to a group composed by sophisticated consumers (especially in the range between 55 and 65 years). Physical well-being and mental well-being have to coexist, because one shouldn't exclude the other objectives in the wellness's research; in relation to this need the search for cures and unconventional therapies that are able to satisfy this desire has increased.

The number of people who uses complementary and alternative medicine is growing. In all the natural medicines, man is seen as a microcosm inside the macrocosm [10]; they argue forcefully that every phenomenon involves the entire system of balances that surrounds the individual. The main objective of this research is to find the choice's determinants (in terms of motivation and desire) of the CAM by older adults consumers.

\section{CAM and Quality of Life in the Older Adults}

The life's quality concept as a measurable entity is relatively recent; it can be described by a series of areas or dimensions of human experience, which is just not about physical conditions and symptoms but also about the ability of an individual to get satisfaction from the daily in relation to their expectations and to their ability to achieve what they want. From medical point of view the concept of life's quality is related to the concept of health, defined as "the set of the life's qualitative aspects of the individual correlated to domains of disease and health, and therefore editable by medicine". The definition of health given by OMS is: "A complete state of, physical, psychological and social well-being, and not just the absence of illness". According to those considerations we have a new idea of wellness, that is not anymore closed and standardized, but related with the new type of consumer of alternative medicine, characterized by multiple self and by multiple demands that which have the purpose of reaching a different life's style. In the last few years the number of people that addresses to unconventional therapies and practices is growing. This adherence to alternative medicine is unmistakable marks of escape from the orthodox scientific medicine, a sign of dispute, dissatisfaction, towards to a medical practice that doesn't respect or forget, indeed, the person's and the individual's overall structure [11]. The need 
for safety and the health's expectations, together with the aspiration of a global well-being, lead to an incessant demand of physical and mental wellness.

These factors together lead the consumer to turn to unconventional medicine. Older adults are turning to complementary and alternative medicine (CAM) but what sets CAM apart from traditional medicine is not only different techniques and medicines but also the way medicine is practiced. "It's not just about what tools are used". CAM practitioners generally relate to their patients with respect, spending lots of time with them and focusing on people's wellness rather than their problems [12] [13]. In conclusion: "For diagnoses that accompany aging such as cancer, neurological diseases, psychiatric disorders, and physical disabilities, CAM has often been used in addition to or in place of unsuccessful conventional methods of treatment. This new and up-to-the-minute compendium of reliable and authoritative information on complementary and alternative therapies seeks to provide information that older adults may use as they seek to improve their health and quality of life" [14]. The field of Complementary and Alternative Medicine (CAM) is expected to grow tremendously in the next few years.

\section{Methodology}

\subsection{Sample and Data Collection Procedures}

The sample consisted in 150 Italian older consumers who used alternative medicine in the last year. The older adults interviewed were 52 males (34.7\%) and 98 females (65.3\%) and the average age of $65.4(S D=0.76)$. Regard to the educational level and income, most participants have high school degrees (67.4\%) and an income ranged from $€ 30.000$ to $€ 70.000$ (71.2\%). Finally, with regard to the profession, most of the participants are retired (79.6\%), followed by university professor (12.4\%) and entrepreneurs/managers (8\%). Participants have been interviewed through a questionnaire containing measures of investigated constructs. The interview was held inside hospital alternative medicine present in Italy.

\subsection{Measure}

\subsubsection{Reasons That Guide the Purchase}

To detect the Hierarchical Value Maps of Bagozzi [15] [16], participants have been asked to list up to five reasons for choosing CAM. Therefore, for every reason, they have been asked to explain the reasons for its importance. Once expressed the reason of the importance, we further asked to explain why it was important just expressed. Were identified 2250 goal that were generated assigned to categories according to the rule of achieve maximal agreement for within categories similarity and between category dissimilarity in the meaning [17] [18]. Four Judge coded all motives and 15 different categories were identified: Adversity to standard care, Product quality, Product quality, High efficacy, Curiosity, Easy of care, Viable alternative, Natural, Organoleptic qualities, Mode, Reliable remedy, Ethical reasons, Hint, Less expensive, Ancient health care, Quality of life.

\subsubsection{Behavioral Basis of Purchase}

To identify behavioral basis of purchase, the intentions and the behavioral variables that influence them were measured [19] [20].

Behavioral intentions. This variable was measured by the item: "How likely are you to repurchase Complementary and Alternative Medicine?”. Participants responded on a 4-point scale from very unlikely to very likely.

Evaluative and affective attitude. Consumers were asked to evaluate the concept "Complementary and Alternative Medicine is" on 177-points semantic differential items [21]: ten assessed evaluation attitude (e.g. "useful-useless") and seven assessed affective attitude (e.g. "pleasant-unpleasant”). The alphas for the affective and evaluative attitude are equal respectively to 0.74 and 0.77 .

Social identity. Participants have been asked to express the relationship between two identities ("Who Buys Complementary and Alternative Medicine" and "Yourself') expressing an opinion on a 7-point scale, from widely separated to completely overlapped [22].

Subjective norms. To detect this construct we asked participants to answer the question "People most important for me endorse my decision to buy Complementary and Alternative Medicine", on a 4-point scale (from completely false to completely true).

Desire. To detect this construct we asked consumers to express their opinion on a 4-point scale (from com- 
pletely false to completely true) on the statement "I would like to buy again Complementary and Alternative Medicine".

Perceived behavioral control. This variable was measured through the statement "If I wish, it would be easy for me to buy more Complementary and Alternative Medicine". Participants responded on a 4-point scale from completely false to completely true.

\subsection{Statistical Analysis}

Measures of reasons that guide the purchase of CAM from older adults were subjected to a series of claim that an arguer provides in defense of position taken. Any argument can be supported directly by multiple claims as evidence. Each claim can be challenged on the basis of its justification. The succession of the reasoning yields a network of support for an argument going from specific to general. The first why-question asked older adults to provide up to five reasons for their consumer choice. After indicating whether or not they would take action respondents were then asked to provide their personal motives for doing so. A semi-structured elicitation procedure was used to uncover distinctive motives and relationship between motives. The specific procedure was an adaptation of the laddering method previously employed by researchers to motives for joining, or re-enlisting in, the military [15].

The behavioral basis of purchase was also examined by regression linear stepwise by software SPSS 21.0. Stepwise linear regression is a method of regressing multiple variables while simultaneously removing those that aren’t important.

\section{Results}

\subsection{Reasons That Guide Purchasing Behavior}

In order to detect the motivational aspects of the consumer choice of CAM, the answers provided by participants were categorized into 15 categories (Table 1). The implication matrix was constructed. This matrix lists reasons,

\section{Table 1. Implication matrix for older adult CAM’s consumer.}

\begin{tabular}{|c|c|c|c|c|c|c|c|c|c|c|c|c|c|c|c|c|c|}
\hline \multicolumn{2}{|c|}{$\begin{array}{c}\text { Abstraction } \\
\text { Ratio }\end{array}$} & \multirow{2}{*}{$\begin{array}{l}1 \\
0\end{array}$} & \multirow{2}{*}{$\begin{array}{l}2 \\
0\end{array}$} & \multirow{2}{*}{$\begin{array}{l}3 \\
1\end{array}$} & \multirow{2}{*}{$\begin{array}{l}4 \\
0\end{array}$} & \multirow{2}{*}{$\begin{array}{l}5 \\
2\end{array}$} & \multirow{2}{*}{$\begin{array}{l}6 \\
0\end{array}$} & \multirow{2}{*}{$\begin{array}{l}7 \\
1\end{array}$} & \multirow{2}{*}{$\begin{array}{l}8 \\
0\end{array}$} & \multirow{2}{*}{$\begin{array}{l}9 \\
0\end{array}$} & \multirow{2}{*}{$\begin{array}{c}10 \\
0\end{array}$} & \multirow{2}{*}{$\begin{array}{l}11 \\
2\end{array}$} & \multirow{2}{*}{$\begin{array}{l}12 \\
0\end{array}$} & \multirow{2}{*}{$\begin{array}{c}13 \\
0\end{array}$} & \multirow{2}{*}{$\begin{array}{l}14 \\
0\end{array}$} & \multirow{2}{*}{$\begin{array}{c}15 \\
6\end{array}$} & \multirow{2}{*}{$\begin{array}{c}\text { Out-degrees } \\
12\end{array}$} \\
\hline 0.809 & 1. Adverse to standard care & & & & & & & & & & & & & & & & \\
\hline 0.529 & 2. Product quality & 0 & 0 & 7 & 0 & 3 & 1 & 23 & 0 & 0 & 0 & 0 & 0 & 0 & 12 & 3 & 49 \\
\hline 0.438 & 3. High efficacy & 15 & 14 & 0 & 0 & 9 & 7 & 11 & 0 & 1 & 6 & 0 & 5 & 0 & 6 & 17 & 91 \\
\hline 0.255 & 4. Curiosity & 8 & 4 & 0 & 0 & 0 & 2 & 2 & 0 & 16 & 0 & 1 & 0 & 0 & 0 & 2 & 35 \\
\hline 0.478 & 5. Easy of care & 0 & 3 & 4 & 0 & 0 & 0 & 23 & 0 & 0 & 8 & 1 & 0 & 0 & 2 & 7 & 48 \\
\hline 0.236 & 6. Viable alternative & 8 & 6 & 2 & 1 & 3 & 0 & 27 & 0 & 1 & 2 & 2 & 1 & 0 & 0 & 2 & 55 \\
\hline 0.576 & 7. Natural & 8 & 14 & 22 & 1 & 15 & 2 & 0 & 0 & 0 & 11 & 1 & 12 & 0 & 9 & 9 & 104 \\
\hline 0.277 & 8. Organoleptic qualities & 0 & 0 & 0 & 0 & 0 & 0 & 4 & 0 & 0 & 1 & 0 & 0 & 0 & 0 & 8 & 13 \\
\hline 0.568 & 9. Mode & 0 & 2 & 3 & 3 & 0 & 0 & 1 & 1 & 0 & 0 & 0 & 4 & 0 & 0 & 2 & 16 \\
\hline 0.610 & 10. Reliable remedy & 4 & 2 & 4 & 0 & 4 & 0 & 5 & 0 & 1 & 0 & 0 & 1 & 1 & 2 & 8 & 32 \\
\hline 0.322 & 11. Ethical reasons & 1 & 1 & 0 & 0 & 0 & 0 & 15 & 0 & 0 & 0 & 0 & 0 & 0 & 0 & 4 & 21 \\
\hline 0.36 & 12. Hint & 4 & 3 & 14 & 4 & 1 & 5 & 4 & 0 & 2 & 0 & 1 & 0 & 0 & 9 & 1 & 48 \\
\hline 0.111 & 13. Less expensive & 1 & 0 & 0 & 0 & 0 & 0 & 1 & 0 & 0 & 6 & 0 & 0 & 0 & 0 & 0 & 8 \\
\hline 0.524 & 14. Ancient health care & 2 & 2 & 7 & 2 & 3 & 0 & 6 & 1 & 0 & 4 & 2 & 4 & 0 & 0 & 7 & 40 \\
\hline \multirow[t]{2}{*}{0.589} & 15. Quality of life & 0 & 4 & 7 & 1 & 4 & 0 & 18 & 3 & 0 & 12 & 0 & 0 & 0 & 4 & 0 & 53 \\
\hline & In-degrees & 51 & 55 & 71 & 12 & 44 & 17 & 141 & 5 & 21 & 50 & 10 & 27 & 1 & 44 & 76 & 625 \\
\hline
\end{tabular}


number of times each reason leads to another reason, the in-degrees (number of times each reason was the subject of a connection), and out-degrees (number of times each reason has been the object and origin). Starting from the matrix of the implications, the hierarchical trees have been constructed. Within the hierarchical tree, the reasons were sorted according to the abstraction index ${ }^{1}$ [15] [16], which expresses the degree to which a reason is the ultimate goal to be reached: the higher the value, the more the reason was abstract. The relationships within the hierarchy tree are those mentioned by at least the $5 \%$ of participants for both groups, that is, those relationships which reach at least a frequency of 7.

Regard to older adults consumers who purchase Alternative and complementary medicine, the most abstract category is "Adverse to standard care", this category is linked to other categories such as "Curiosity", "Mode", "High efficacy" and "Viable alternative". Therefore, it seems that the first choice orientation is tied mostly to the concept of quality and desire of alternative care. A second orientation that could be defined as more "Practical" is "High efficacy". This category, which is also the most central ${ }^{2}$ is connected to other categories such as "Product quality", "Natural", "Hint”, "Quality of life", "Easy of care" and "Viable alternative”. It points out another order of important reasons for the older adult Cam's consumer, is the desire a treatment that delivers a better life's quality (Figure 1).

\subsection{The Behavioral Basis of Purchase}

As regards the variables that affect the intention to repurchase the product (subjective norms, perceived behavioral control, desire, social identity, evaluative and affective attitude) a stepwise linear regression was applied (Table 2).

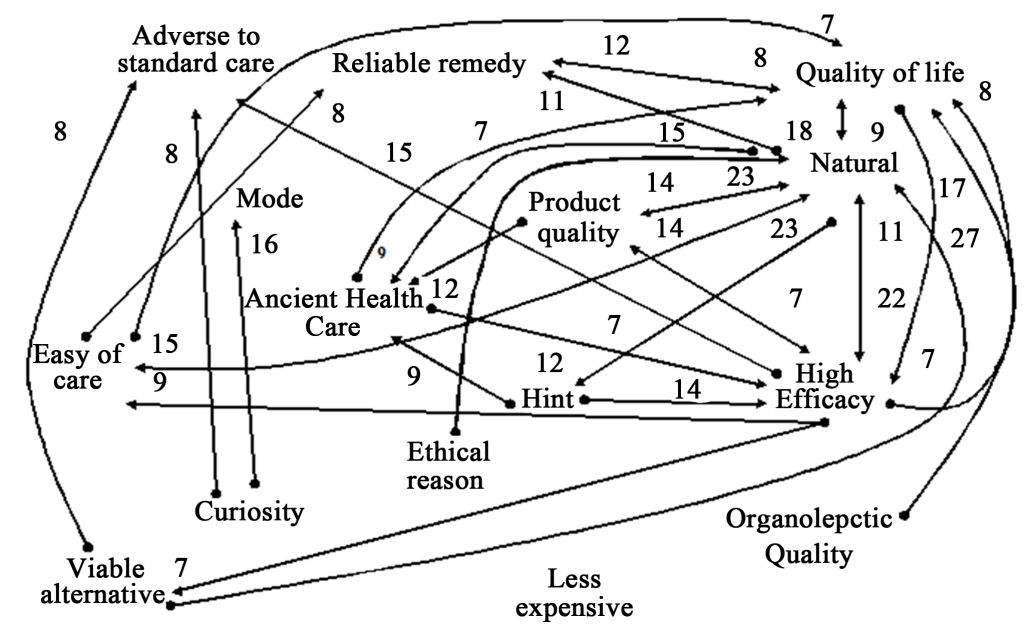

Figure 1. Cognitive maps of reasons for older adult CAM's consumer $(N=150$; cut off $=8)$. The most abstract category is "Adverse to standard care".

Table 2. Stepwise linear regression for older adults that consumer CAM. Dependent variable: intention.

\begin{tabular}{ccccc}
\hline Step & Variables & Beta & $R^{2}$ & $R^{2}$ Change \\
\hline 1 & Desire & $0.87^{* * *}$ & $0.76^{* * *}$ & \\
2 & Desire & $0.69^{* * *}$ & & $0.81^{* * *}$ \\
& Perceived behavioral control & $0.29^{* * *}$ & $0.05^{*}$ \\
\hline
\end{tabular}

Note. Betas are standardized coefficients. ${ }^{*} p<0.05 ;{ }^{* *} p<0.01 ;{ }^{* * *} p<0.001$.

\footnotetext{
${ }^{1}$ The general formula for computing abstraction ratio can be written as: In-degrees/In-degrees + Out-degrees. The abstractness ratio measures the proportion of times a motive serve a destination or end in a linkage, as opposed to a source [18]. The assumption is "that the more abstract a motive, the more likely it will be an end motive. A value of 1.00 for a motive on the abstractness ratio can be considered a grounding motive" [18].

${ }^{2}$ The general formula for computing index of centrality is: Out-degree + In-degree/total relation [15]. Index of centrality measure how frequently a particular motive is involved in linkages with other motives.
} 
Regarding older adults consumers who buy alternative and complementary medicine, the purchase intent derived largely desire, followed by perceived behavioral control. The symbolic focus of consumption in postmodernity is desire, these desires are constructed through the symbolic linkage between consumption and research of wellness.

\section{Discussion}

The most important innovation of consumerism today is the interaction that the consumer establishes with the self and identity. The first concept that allows to read these elements, is the belief that the consumer society begins when the means of production allow a surplus of product compared to the wealthy purchasing power, which until then had been directed to the proposal of consumption [23]. Simultaneously, a process intended to change the socio-cultural ethics of worker starts and it emerges as an earthly vision that narrows the horizon at hic et nunc of happiness permitted by consumption and social complicity [24]. One of the consequences of these changes in perspective and meaning, is observable since in a growing interests by the consumer to the different medical practices also called "official”. The last years, indeed, are characterized by the explosion of this phenomenon, diversified in different areas of consumption: homeopathy, alternative medicine and physiotherapy. The behavior's styles belonging to this type of consumption begin to emerge in the nineties, when it develops and is promoted the adherence to the principles of social ethics orientated to the respect for person and the care of physical and mental wellbeing. Nowadays, unlike in the 80s, period in which the consumerism was considered a way to promote the personal identity and the research of new lifestyles, much consumers prefer the consume of the "being" rather than the consume of "ostentation" [25], choosing therefore to be projected, in a increasing way, in the direction of the so called, "consumerism ecology". This is based mainly on the research of a collective wealth, as well as the individual one, and the spread attention to financial, social, and ethic aspects related to consumerism. With the coming of the post-modern society, so there has been a transformation of the related social and cultural aspects which has affected the individual and collective sensibility introducing different theoretical and pragmatic variations, at the values of our society. The results identify the motivations leading individuals to turn to alternative medicine, confirming this phenomenon's growing. Moreover they shows the evolution of the consumer as actor of the decision-making process and also as a supporter of the market; in this way he would be able to satisfy the self needs and to comply with the New consumption's symbol.

The hope of being able to rely on a medicine more "welfare-oriented" because "natural", is strongly linked to the dissatisfaction of traditional methods that are invasive and aseptic to consumer's eyes.

The results of this study showed a strong dissatisfaction of respondents with the traditional medical treatments because they are considered more invasive. Objective of this research was to investigate motivational, cognitive, and behavioral aspects leading the older adult consumers of CAM to purchase the product. Some considerations deserve to be mentioned. Regarding to the reasons that guide the purchasing behavior: older adults consumers are oriented to the choice by "Adverse traditional care" that is linked to other categories such as "Quality of life", "Alternative" and "Hint". Therefore, it seems that the first choice orientation is tied mostly to the concept of quality and health. The hope to rely upon a natural medicine oriented toward individual's well-being is strongly related with the consumer's in satisfaction with traditional cure, which are considered as invasive and impersonal.

\section{Conclusion}

Finally, with regard to the behavioral bases of purchase, older adult consumers choose CAM to repurchase products especially because they receive pleasure; this is determined by a process of identification that the older adults build up with the CAM, by the growing desire that they will be mature in relation to this brand and by the "belief that they may be able to develop and perform a certain behaviour in relation to it" [19]. The limitation of the study presented certainly relates to the small number of older adults we interviewed, which does not allow us to assert whether our findings are reliable within a national context, whether there is an orientation toward the consumption of the type indicated in the results, or whether other indications emerge. In this sense, we intend in the future to overcome this limitation by expanding the research sample size, involving other Italian regions.

\section{References}

[1] Foster, D.F., Phillips, R.S., Hamel, M.B. and Eisenberg, D.M. (2000) Alternative Medicine Use in Older Americans. Journal of American Geriatric Society, 48, 1560-1565. http://dx.doi.org/10.1111/j.1532-5415.2000.tb03864.X 
[2] Grzywacz, J.G., Suerken, C.K., Quandt, S.A., Bell, R.A., Lang, W. and Arcury, T.A. (2006) Older Adults’ Use of Complementary and Alternative Medicine for Mental Health: Findings from the 2002 National Health Interview Survey. The Journal of Alternative and Complementary Medicine, 12, 467-473. http://dx.doi.org/10.1089/acm.2006.12.467

[3] Gillespie, L.D., Robertson, M., Gillespie, W.J., Sherrington, C., Gates, S., Clemson, L.M. and Lamb, S.E. (2012) Interventions for Preventing Falls in Older People Living in the Community. The Cochrane Collaboration. John Wiley \& Sons, Ltd., Hoboken.

[4] Siri, G. (2001) La psiche del consumo [The Psyche of the Consumer]. Franco Angeli, Milano.

[5] Siri, G. (2004) Psicologia del consumatore. Consumi e costruzione del significato [Consumer Psychology. Consumption and Construction of Meaning]. Mc Graw Hill, Milano.

[6] Siri, G. and Rutelli, P. (2004) Consumi e personalità [Consumption and the Personality]. In: Siri, G. (a cura di), Ed., Psicologia del consumatore, Consumi e costruzione del significato [Consumer Psychology. Consumption and Construction of Meaning], McGraw-Hill, Milano, 99-127.

[7] Marcellini, F., Gagliardi, C., Leonardi, F. and Spazzafumo, L. (1999) Mobilità e qualità della vita degli anziani [Mobility and Quality of Life of Older People]. Franco Angeli, Milano.

[8] Breveglieri, L. and Mauri, L. (1996) Vivere l'età anziana [Live Old Age]. Franco Angeli, Milano.

[9] Poles, B. (2010) Help the ageing! Anziani nuovi stili di vita e consumo [Help the Aging! Older New Lifestyles and Consumption]. Panorama per i giovani, 2, 18-21.

[10] Cheung, C.K., Wyman, J.F. and Halcon, L.L. (2007) Use of Complementary and Alternative Therapies in Community-Dwelling Older Adults. The Journal of Alternative and Complementary Medicine, 13, 997-1006. http://dx.doi.org/10.1089/acm.2007.0527

[11] Schnabel, K., Binting, S., Witt, C.M. and Teut, M. (2014) Use of Complementary and Alternative Medicine by Older Adults-A Cross-Sectional Survey. BMC Geriatrics, 14, 38. http://dx.doi.org/10.1186/1471-2318-14-38

[12] Orzech, D. (2007) Complementary and Alternative Medicine for Older Adults. Social Work Today, 7, 38.

[13] Behrman, G. and Tebb, S. (2009) The Use of Complementary and Alternative Interventions as a Holistic Approach with Older Adults. Journal of Religion and Spirituality in Social Work: Social Thought, 28, 127-140. http://dx.doi.org/10.1080/15426430802644156

[14] Mackenzie, E.R. and Rakel, B. (2006) Complementary and Alternative Medicine for Older Adults: A Guide to Holistic Approaches to Healthy Aging. Springer, New York.

[15] Bagozzi, R.P., Bergami, M. and Leone, L. (2003) Hierarchical Representation of Motives in Goal-Setting. Journal of Applied Psychology, 88, 915-943. http://dx.doi.org/10.1037/0021-9010.88.5.915

[16] Bagozzi, R.P. and Edwards, J.R. (1998) A General Approach for Representing Constructs in Organizational Research. Organizational Research Methods, 1, 45-87. http://dx.doi.org/10.1177/109442819800100104

[17] Smith, E.E., Patalano, A.L. and Jonides, J. (1998) Alternative Strategies of Categorization. Cognition, 65, $167-196$. http://dx.doi.org/10.1016/S0010-0277(97)00043-7

[18] Bagozzi, R.P., Sekerka, L.E. and Hill, V. (2009) Hierarchical Motive Structures and Their Role in Moral Choices of Managers. Journal of Business Ethics, 90, 461-486. http://dx.doi.org/10.1007/s10551-010-0601-3

[19] Bagozzi, R.P. (1999) Atteggiamenti intenzioni e comportamento: L'analisi e la previsione dell'agire individuale in ambito psico-sociale ed economico [Attitude Intentions and Behavior: The Analysis and Prediction of Individual Action in the Field of Psycho-Social and Economic]. Franco Angeli, Milano.

[20] Bagozzi, R.P., Gurhan-Canli, Z. and Priester, J.R. (2002) The Social Psychology of Consumer Behavior. Open University, Milton Keynes.

[21] Osgood, C.E. (1957) A Behavioristic Analysis of Perception and Language as a Cognitive Phenomena. In: Bruner, J.S., et al., Eds., Contemporary Approach to Cognition, Harvard University Press, Cambridge, 75-118.

[22] Bergami, M. and Bagozzi, R.P. (2000) Self-Categorization and Affective Commitment and Group Self-Esteem as Distinct Aspects of Social Identity in the Organization. British Journal of Social Psychology, 39, 555-577. http://dx.doi.org/10.1348/014466600164633

[23] Fabris, G. (2003) Il nuovo consumatore verso il postmoderno [The New Consumer to the Postmodern]. Franco Angeli, Milano.

[24] Platania, S., Santisi, G. and Hichy, Z. (2012) Determinants of Consumer Choice towards Luxury Brands: Differences between One-Brand Stores and Outlet-Stores Consumers. In: Gasiorowska, A. and Zaleskiewicz, T., Eds., Microcosm of Economic Psychology, Proceedings of the IAREP Conference Wroclaw 2012, Warsaw School of Social Sciences and Humanities, Faculty in Wroclaw, Wroclaw, 332-339.

[25] Santisi, G., Platania, S. and Hichy, Z. (2014) A Lifestyle Analysis of Young Consumers: A Study in Italian Context. Young Consumers, 15, 94-104. http://dx.doi.org/10.1108/YC-03-2013-00357 